\title{
Effects of four single nucleotide polymorphisms of $E Z H 2$ on cancer risk: a systematic review and meta-analysis
}

\author{
Zhixin Ling ${ }^{1,2, *}$ \\ Zonghao You ${ }^{1,2, *}$ \\ Ling $\mathrm{Hu}^{3}$ \\ Lei Zhang ${ }^{1,2}$ \\ Yiduo Wang ${ }^{1,2}$ \\ Minhao Zhang ${ }^{1,2}$ \\ Guangyuan Zhang ${ }^{1,2}$ \\ Shuqiu Chen ${ }^{1,2}$ \\ Bin $X u^{1,2}$ \\ Ming Chen ${ }^{1,2}$ \\ 'Department of Urology, Affiliated \\ Zhongda Hospital of Southeast \\ University, Nanjing, China; ${ }^{2}$ Surgical \\ Research Center, Institute of \\ Urology, Medical School of \\ Southeast University, Nanjing, China; \\ ${ }^{3}$ Department of Nephrology, People's \\ Hospital of Wuxi City, Wuxi, China \\ *These authors contributed equally \\ to this work
}

This article was published in the following Dove Press journal: OncoTargets and Therapy

Background: Although the relationship between several single nucleotide polymorphisms (SNPs) of the oncogene $E Z H 2$ and cancer risk has been assessed by some case-control studies, results of subsequent studies are controversial. Sample sizes from single-center studies are also limited, thereby providing unreliable findings. Hence, we conducted a comprehensive search and meta-analysis to evaluate the associations between EZH2 SNPs and cancer risk.

Materials and methods: A comprehensive literature search for studies focusing on $E Z H 2$ SNPs and cancer risk was conducted on PubMed, Web of Science, Embase, and China National Knowledge Infrastructure online databases. Genotype data were extracted and examined through a meta-analysis, and pooled odds ratios (ORs) with 95\% CIs were used to assess the corresponding associations. Sensitivity analysis, publication bias assessment, and heterogeneity test were performed using STATA 12.0.

Results: Twelve eligible studies were included in this meta-analysis. The association of 4 SNPs, namely, rs887569, rs2302427, rs3757441, and rs41277434, in the EZH2 locus with cancer risk was evaluated. Five studies (1,794 cases and 1,878 controls) indicated that rs887569 was related to a decreased cancer risk (CTTT/CC: $\mathrm{OR}=0.849,95 \% \mathrm{CI}$ : [0.740 to 0.973 ], $P=0.019$; TT/CCCT: OR $=0.793,95 \% \mathrm{CI}$ : [0.654 to 0.962], $P=0.019)$. Seven studies $(2,408$ cases and 2,910 controls) showed that rs2302427 was linked to a decreased cancer risk $(\mathrm{GG} / \mathrm{CC}$ : $\mathrm{OR}=0.562,95 \% \mathrm{CI}$ : $[0.400$ to 0.792$], P=0.001 ; \mathrm{CGGG} / \mathrm{CC}: \mathrm{OR}=0.856,95 \% \mathrm{CI}:[0.748$ to 0.980], $P=0.024$; GG/CCCG: $\mathrm{OR}=0.733,95 \% \mathrm{CI}$ : [0.571 to 0.940 ], $P=0.015$ ). No relationships were observed between rs3757441 or rs41277434 and cancer risk.

Conclusion: rs 887569 and rs 2302427 in EZH2 may be correlated with a decreased cancer risk. Although rs3757441 and rs41277434 are independent risk factors of cancer, further large-scale and functional studies are warranted to validate our findings.

Keywords: EZH2, single nucleotide polymorphism, cancer risk, meta-analysis

\section{Introduction}

Approximately 1,688,780 new cancer cases and 600,920 cancer deaths are projected to occur in the USA in $2017 .{ }^{1}$ Cancer is caused by uncontrolled cell division or inappropriate survival of a cell with DNA damage, which is critical for tumor initiation and progression.

Thousands of genes that are either transcriptionally upregulated or downregulated in tumor samples have been identified through microarray analysis, indicating that cancer is a disease with extreme heterogeneity. These deregulations act as the main drivers that enable tumors to invade cellular barriers, proliferate, and metastasize. ${ }^{2}$ The dynamic regulation of histone modifications in promoters and enhancers plays a vital role in the
Correspondence: Bin Xu; Ming Chen Zepartment of Urology, Affiliated

University, No 87, Dingjiaqiao, Gulou

District, Nanjing, Jiangsu 210009, China

Tel +86 I80 I294 9196;

+86 I39 I3009977

Email njxb1982@।26.com;

mingchenseu@।26.com
OncoTargets and Therapy 2018:1/ 85I-865

(c) (1) (2) ( 2018 Ling et al. This work is published and licensed by Dove Medical Press Limited. The full terms of this license are available at https://www.dovepress.com/terms.php cc. hereby accept the Terms. Non-commercial uses of the work are permitted without any further permission from Dove Medical Press Limited, provided the work is properly attributed. For permision for commercial use of this work, please see paragraphs 4.2 and 5 of our Terms (https://www.doveppess. com/terms.php). 


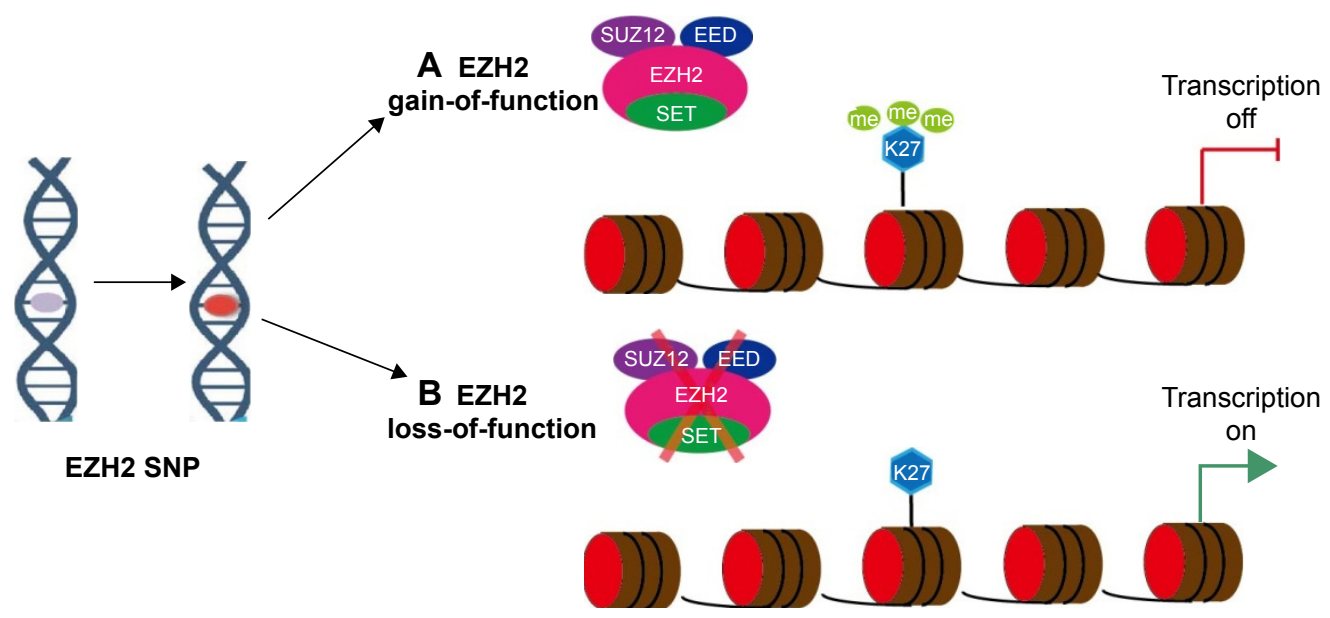

Figure I EZH2 polymorphism affects transcription of downstream targets.

Abbreviation: SNP, single nucleotide polymorphism.

control of gene expression and consequently affects disease susceptibility. EZH2 has been widely investigated because it serves as a master regulator of cancer epigenetics. ${ }^{3}$ It is also a core component of Polycomb repressive complex 2, which mainly methylates lysine 27 of histone H3 (H3K27) to induce transcriptional gene silencing. ${ }^{4} \mathrm{EZH} 2$ overexpression causes epigenetic alterations in tumor suppressor genes, and such changes are required for cancer proliferation, migration, invasion, and metastasis..$^{5-7}$ Therefore, aberrant EZH2 activities may participate in increasing the risk of tumorigenesis.

The oncogenic role of EZH2 has been observed in numerous cancers, including prostate cancer, bladder cancer, breast cancer, and melanoma, whose high EZH2 expression levels are positively correlated with poor survival rate and aggressiveness. ${ }^{8-11}$ The function of EZH2 in cancer progression may also be affected by mutations. For example, the mutation of tyrosine 641 (Y641) within the C-terminal catalytic SET domain of EZH2 increases the levels of trimethylated H3K27 (H3K27me3) and thus represses the expression of Polycomb targets. ${ }^{12}$ The loss-of-function mutations of EZH2 may occur during cancer development. The frequency of missense mutations of $E Z H 2$ in the pediatric subtype of human T-cell acute lymphoblastic leukemia (T-ALL) and early T-cell precursor (ETP) ALL is higher than that in non-ETP pediatric T-ALL. ${ }^{13,14}$ Similarly, single nucleotide polymorphisms (SNPs) of EZH2 may have different effects on disease susceptibility through the transcriptional regulation of genes involved in cancer initiation and progression (Figure 1). Although several studies have investigated the relationship of 4 SNPs (rs887569 C $>$ T, rs2302427 C $>$ G, rs3757441 T $>$ C, and rs41277434 A $>$ C) of EZH2 and cancer risk, results are inconsistent. This relationship has yet to be systematically investigated, and definitive conclusions have yet to be presented. Hence, comprehensive reviews and meta-analyses should be performed. Here, we conducted a meta-analysis to precisely assess and provide a comprehensive conclusion about the associations between $E Z H 2$ variations and cancer risk from all eligible case-control studies published to date.

\section{Materials and methods Search strategy and identification of eligible studies}

Two reviewers (Ling and You) searched the online databases PubMed, Google Scholar, Web of Science, Embase, China National Knowledge Infrastructure (CNKI), and Wangfang Data to identify relevant articles published until September 2017. The following search terms were used either separately or in combination: "EZH2, enhancer of zeste homolog 2," "rs887569, rs2302427, rs3757441, rs41277434," "cancer, carcinoma, neoplasm," "tumor, tumour," and "SNP, polymorphism, allele, variation." Studies were limited to articles published in Chinese or English, and the references of pertinent articles were manually screened and checked. Articles that satisfied the following criteria were included: 1) studies that assessed the association between a SNP from EZH2 (rs887569, rs2302427, rs3757441, and rs41277434) and cancer risk; 2) case-control or population-based studies; and 3) studies with available genotype frequencies. Studies were excluded according to the following criteria: 1) articles that were presented as a systematic review or focusing on animals; 2) studies that involved DNA extracted from cancer tissues rather than blood samples, or studies that did not provide usable data for meta-analysis; and 3) studies that 


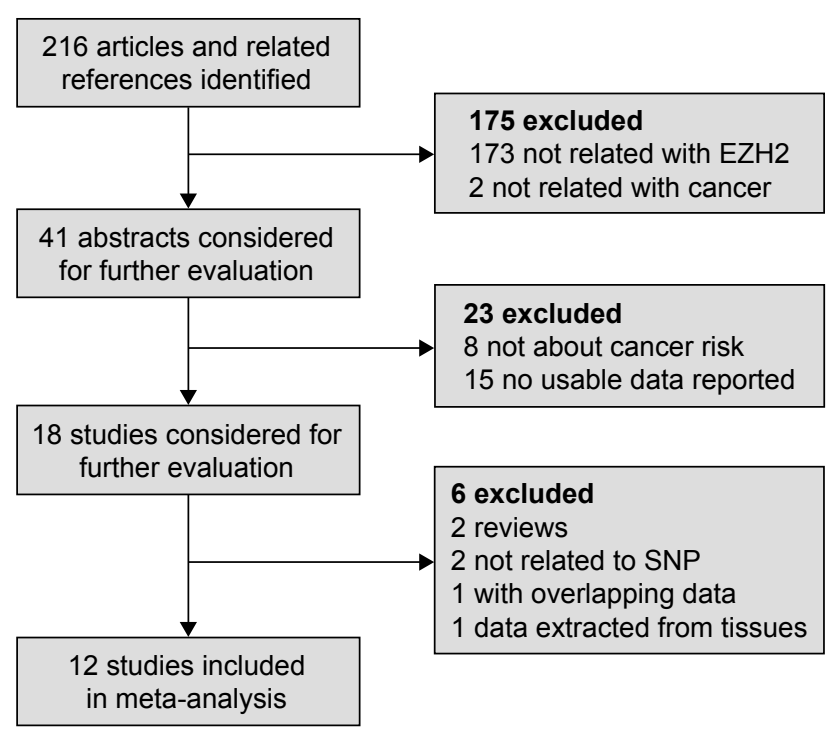

Figure 2 Studies identified with criteria of inclusion and exclusion. Abbreviation: SNP, single nucleotide polymorphism.

reported data overlapping with those described in the included studies.

\section{Data extraction}

Two reviewers (Ling and You) independently extracted the following information from each study: first author, year of publication, cancer types, country or region, ethnicity, genotype detection method, control source of each study, number of cases and controls, polymorphism site included in each study, and results of Hardy-Weinberg equilibrium (HWE). Inconsistencies were resolved by discussion until a consensus was obtained. Newcastle-Ottawa Quality Assessment Scale was used to examine the quality of the articles included in this study. ${ }^{15}$

\section{Statistical analysis}

The strength of the association between SNPs and cancer risk was evaluated by determining the odds ratio (OR) with 95\% CI, which was calculated by Z-test, and the result of the pooled $\mathrm{OR}$ was considered significant when $P<0.05$. This association was also examined by using homozygote, heterozygote, dominant genetic, and recessive genetic models. Subgroup analyses were conducted according to cancer types and ethnic groups. Heterogeneity between articles was identified with $Q$-test and $I^{2}$ index. ${ }^{16}$ When heterogeneity was observed $\left(P<0.05\right.$ or $\left.I^{2}>50 \%\right)$, a random-effect model (DerSimonian-Laird method) was applied; otherwise, a fixed-effect model (Mantel-Haenszel method) was utilized. ${ }^{17,18}$ Publication bias was evaluated by Egger's test and Begg's test, with a $P$-value $>0.05$ considered evidence

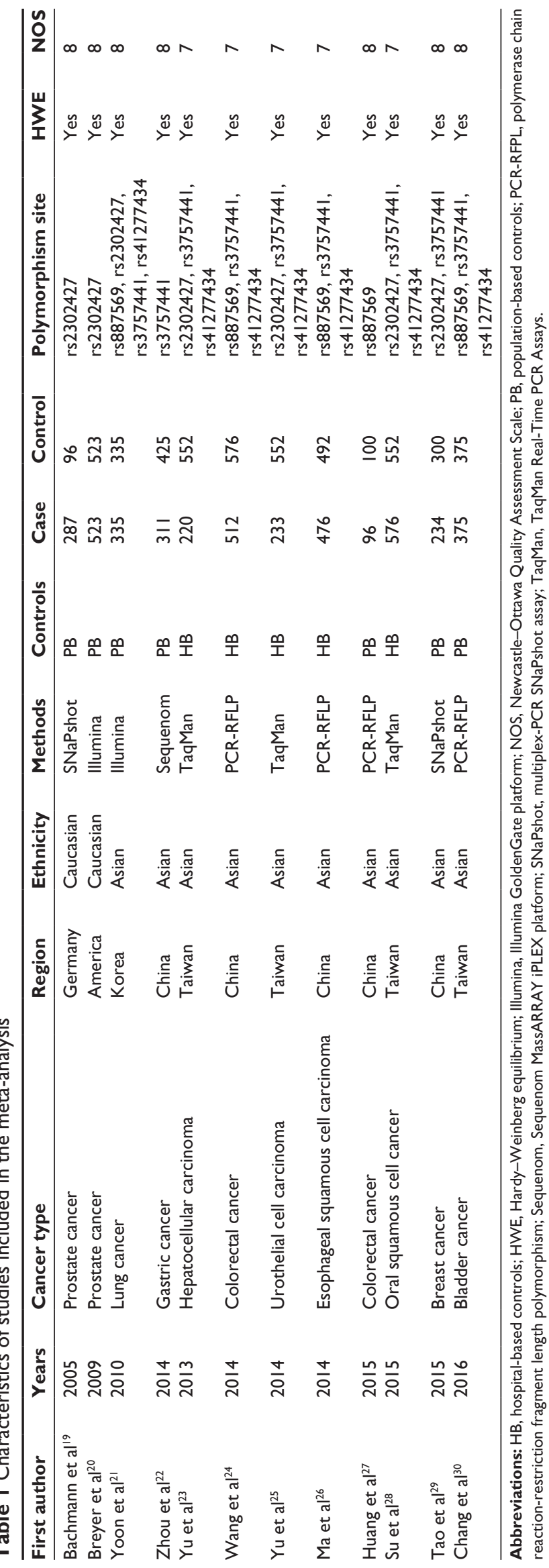


Table 2 Analysis of associations between SNPs of EZH2 and cancer risk

\begin{tabular}{|c|c|c|c|c|c|c|c|}
\hline \multirow[t]{2}{*}{ Comparisons } & \multirow[t]{2}{*}{ Study } & \multirow[t]{2}{*}{$\mathbf{N}^{\mathbf{a}}$} & \multirow{2}{*}{$\begin{array}{l}\text { Cases/ } \\
\text { controls }\end{array}$} & \multirow{2}{*}{$\frac{\text { WM vs WW' }}{\text { OR }(95 \% \mathrm{Cl})}$} & \multirow[t]{2}{*}{$P$-value ${ }^{c}$} & \multirow[t]{2}{*}{$I^{2}, \%$} & \multirow{2}{*}{$\frac{\text { MM vs WW' }}{\text { OR }(95 \% \mathrm{CI})}$} \\
\hline & & & & & & & \\
\hline rs887569 C>T & Overall (Asian) & 5 & $\mathrm{I}, 794 / \mathrm{I}, 878$ & $0.889(0.77$ I to I.026) & 0.466 & 0.0 & 0.738 (0.520 to I.047) \\
\hline Cancer type & DSC & 3 & $1,084 / 1,168$ & 0.923 (0.764 to I.115) & 0.260 & 25.7 & 0.878 (0.533 to I.445) \\
\hline rs $2302427 \mathrm{C}>\mathrm{G}$ & Overall & 7 & $2,408 / 2,910$ & 0.866 (0.696 to I.077) & 0.051 & 52.0 & $0.562(0.400$ to 0.792$)$ \\
\hline \multirow[t]{2}{*}{ Ethnicity } & Asian & 5 & $1,598 / 2,29 \mid$ & 0.937 (0.733 to I.197) & 0.093 & 49.8 & $0.550(0.384$ to 0.787$)$ \\
\hline & Caucasian & 2 & $810 / 619$ & $0.686(0.5$ I I to 0.92 I $)$ & 0.601 & 0.0 & $0.723(0.226$ to 2.313$)$ \\
\hline \multirow[t]{2}{*}{ Cancer type } & DSC & 2 & $796 / 1,104$ & $1.132(0.925$ to 1.385$)$ & 0.958 & 0.0 & $0.618(0.394$ to 0.970$)$ \\
\hline & USC & 3 & $1,033 / 1,362$ & $0.684(0.546$ to 0.857$)$ & 0.872 & 0.0 & $0.484(0.248$ to 0.943$)$ \\
\hline rs375744I T $>C$ & Overall (Asian) & 9 & $3,272 / 4,159$ & 0.938 (0.849 to I.036) & 0.202 & 27.2 & 0.827 (0.555 to I.23I) \\
\hline \multirow[t]{2}{*}{ Cancer type } & DSC & 5 & $2,905 / 2,579$ & 0.947 (0.806 to I.177) & 0.068 & 54.2 & $0.947(0.513$ to 1.748$)$ \\
\hline & USC & 2 & $608 / 927$ & $0.937(0.75$ I to I.169) & 0.538 & 0.0 & $0.8 I$ I (0.563 to I.170) \\
\hline$r s 41277434 \mathrm{~A}>C$ & Overall (Asian) & 7 & $2,727 / 3,403$ & $1.050(0.908$ to 1.213$)$ & 0.990 & 0.0 & $1.044(0.812$ to 1.240$)$ \\
\hline \multirow[t]{2}{*}{ Cancer type } & DSC & 4 & $\mathrm{I}, 784 / 2,172$ & I.04I (0.872 to I.242) & 0.855 & 0.0 & 0.97 I (0.755 to I.247) \\
\hline & USC & 2 & $608 / 927$ & I.045 (0776 to I.408) & 0.996 & 0.0 & 1.705 (0.717 to 1.595$)$ \\
\hline
\end{tabular}

Notes: ${ }^{a}$ Number of comparisons; ${ }^{b} \mathrm{~W}$, major allele; $\mathrm{M}$, minor allele. ${ }^{\mathrm{C}}$-value of $Q$-test of heterogeneity test. DSCs, including hepatocellular carcinoma, oral squamous cell cancer, colorectal cancer, esophageal squamous cell carcinoma, or gastric cancer; USCs, including urothelial cell carcinoma, prostate cancer, bladder cancer. Random-effects models were used if heterogeneity between articles was reported $\left(P<0.10, P^{2}>50 \%\right)$, otherwise fixed-effects models were applied. WM, WW, MM represent heterozygote, homozygote for major allele and homozygote for minor allele, respectively. Bold data is statistically significant.

Abbreviations: DSC, digestive system cancer; USC, urogenital system cancer.

for no potential publication bias. Begg's or Egger's test was performed only for SNPs involved in 5 or more studies. Statistical tests were 2-sided, and analyses were carried out with Stata 12.0 at least twice.

\section{Results}

\section{Characteristics of the included studies}

After PubMed, Google Scholar, Web of Science, Embase, CNKI, and Wangfang Data online databases were extensively screened, 216 relevant articles were identified. As shown in the flowchart in Figure 2, 12 case-control studies involving the 4 EZH2 SNPs were finally included for further meta-analysis after ineligible articles were excluded according to our inclusion and exclusion criteria. ${ }^{19-30}$ The characteristics of the included studies are summarized in Table 1. Of the 12 included studies, 6 focused on digestive system cancers (DSCs; gastric cancer, hepatocellular carcinoma, colorectal cancer [CRC], and esophageal squamous cell carcinoma), 4 examined urogenital system cancers (USCs; prostate cancer, urothelial cell carcinoma, and bladder cancer), and 2 investigated other types of cancers. The detailed information of the analyzed articles for each SNP is shown in Table $\mathrm{S} 1$.

\section{Quantitative synthesis}

The associations between EZH2 SNPs and human cancer risks were evaluated (Table 2; Figures 3 and 4). Overall, the $E Z H 2$ rs $887569 \mathrm{C}>\mathrm{T}$ polymorphism was significantly associated with a decreased cancer risk in the dominant and recessive models (CTTT/CC: $\mathrm{OR}=0.849,95 \% \mathrm{CI}$ : $[0.740$ to 0.973 ], $P=0.019$; TT/CCCT: $\mathrm{OR}=0.793,95 \% \mathrm{CI}$ : 0.654 to 0.962$], P=0.019)$. $\mathrm{EZH} 2 \mathrm{rs} 2302427 \mathrm{C}>\mathrm{G}$ polymorphism was also related to the decreased overall cancer risk in the homozygote dominant genetic and recessive genetic models (GG/CC: $\mathrm{OR}=0.562,95 \%$ CI: $[0.400$ to 0.792$], P=0.001$; CGGG/CC: $\mathrm{OR}=0.856,95 \%$ CI: [0.748 to 0.980$], P=0.024$; GG/CCCG: OR $=0.733,95 \% \mathrm{CI}$ : [0.571 to 0.940$], P=0.015$ ). In other genotype models, such a relationship remains controversial.

Subgroup analysis revealed that the variant $\mathrm{CG}(\mathrm{OR}=0.686$, 95\% CI: [0.511 to 0.921$], P=0.012)$ and $\mathrm{CG} / \mathrm{GG}(\mathrm{OR}=0.688$, 95\% CI: [0.515 to 0.917 ], $P=0.01)$ genotypes of rs 2302427 $\mathrm{C}>\mathrm{G}$ polymorphism were associated with a decreased cancer risk compared with the wild-type $\mathrm{CC}$ genotype in individuals of Caucasian descent. rs $2302427 \mathrm{C}>\mathrm{G}$ polymorphism in Asian descent was linked to the decreased overall cancer risk in the homozygote and recessive genetic models (GG/CC: OR $=0.550,95 \%$ CI: [0.384 to 0.787$], P=0.001 ; \mathrm{GG} / \mathrm{CCCG}: \mathrm{OR}$ $=0.731,95 \%$ CI: [0.566 to 0.944$], P=0.016$ ).

We also conducted a stratified analysis of the data in terms of cancer types, namely, USCs and DSCs. With regard to subgroup analysis of USCs, our results did not show any association of rs887569 $\mathrm{C}>\mathrm{T}$ polymorphism with cancer risk in any genotype model. However, rs2302427 C > G polymorphism was correlated with a decreased cancer risk in homozygote and recessive genetic models for DSCs. As for USCs, similar results were observed in homozygote, heterozygote, and dominant genetic models.

For rs3757441 $\mathrm{T}>\mathrm{C}$ and rs41277434 $\mathrm{A}>\mathrm{C}$ polymorphisms, 9 and 7 studies were included, respectively. 


\begin{tabular}{|c|c|c|c|c|c|c|c|}
\hline \multirow[t]{2}{*}{$P$-value ${ }^{c}$} & \multirow[t]{2}{*}{$I^{2}, \%$} & $W M+M M$ vs $W^{b} W^{b}$ & \multirow[t]{2}{*}{$P$-value ${ }^{c}$} & \multirow[t]{2}{*}{$I^{2}, \%$} & MM vs WM + WW' & \multirow[t]{2}{*}{$P$-value ${ }^{c}$} & \multirow[t]{2}{*}{$I^{2}, \%$} \\
\hline & & OR (95\% Cl) & & & OR (95\% CI) & & \\
\hline 0.058 & 56.2 & $0.849(0.740$ to 0.973$)$ & 0.29 & 19.6 & 0.793 (0.654 to 0.962$)$ & 0.162 & 38.9 \\
\hline 0.068 & 62.8 & 0.894 (0.746 to I.07I) & 0.179 & 41.9 & 0.877 (0.696 to I. 104$)$ & 0.186 & 40.6 \\
\hline 0.967 & 0.0 & $0.856(0.748$ to 0.980$)$ & 0.089 & 45.4 & $0.733(0.57$ I to 0.940$)$ & 0.621 & 0.0 \\
\hline $0.88 I$ & 0.0 & 0.911 (0.782 to I.06I) & 0.098 & 49.0 & 0.73 I (0.566 to 0.944$)$ & 0.356 & 0.0 \\
\hline 0.914 & 0.0 & $0.688(0.5 \mid 5$ to $0.9 \mid 7)$ & 0.627 & 0.0 & 0.768 (0.240 to 2.456$)$ & 0.898 & 0.0 \\
\hline 0.558 & 0.0 & 1.045 (0.862 to I.267) & 0.927 & 0.0 & $0.593(0.380$ to 0.925$)$ & 0.547 & 0.0 \\
\hline 0.733 & 0.0 & $0.664(0.534$ to 0.826$)$ & 0.837 & 0.0 & $0.533(0.274$ to 1.035$)$ & 0.769 & 0.0 \\
\hline 0.000 & 81.3 & 0.915 (0.774 to I.08I) & 0.002 & 67.0 & $0.846(0.599$ to 1.193$)$ & 0.000 & 77.6 \\
\hline 0.000 & 87.7 & 0.976 (0.743 to I.282) & 0.001 & 80.0 & $0.946(0.562$ to 1.592$)$ & 0.000 & 85.0 \\
\hline 0.881 & 0.0 & 0.912 (0.739 to I.125) & 0.625 & 0.0 & 0.817 (0.575 to I.I60) & 0.845 & 0.0 \\
\hline 0.986 & 0.0 & 1.037 (0.905 to I.187) & 0.988 & 0.0 & $0.957(0.79 \mid$ to 1.158$)$ & 0.948 & 0.0 \\
\hline 0.928 & 0.0 & 1.017 (0.860 to I.203) & $0.88 I$ & 0.0 & 0.920 (0.738 to I.I 48$)$ & 0.827 & 0.0 \\
\hline 0.851 & 0.0 & $1.049(0.807$ to 1.365$)$ & 0.913 & 0.0 & $1.056(0.718$ to 1.554$)$ & 0.856 & 0.0 \\
\hline
\end{tabular}

No evidence suggested that these 2 SNPs might be associated with cancer risk either in overall or subgroup analysis $(P>0.05$; Table 2; Figures S1 and S2).

\section{Sensitivity analysis and publication bias assessment}

Sensitivity analyses were conducted by omitting each individual article to measure its specific effect on the pooled ORs (Figure S3). The sensitivity analysis forest plot indicated that no single study significantly affected the pooled ORs for any genetic models of the 4 SNPs. A random-effect model was used when obvious heterogeneity was observed $\left(P<0.05\right.$ or $\left.I^{2}>50 \%\right)$; otherwise, a fixed-effect model was applied. Considering the small number of studies included in the meta-analysis, we conducted Begg's and Egger's tests to assess the publication bias for each genetic model of the 4 SNPs. No evidence of publication bias was detected in any of the homozygote, heterozygote, and dominant and recessive models of each SNP except rs3757441 and rs41277434 (Table 3).

\section{Discussion}

EZH2 overexpression is a marker of advanced and metastatic diseases in many solid tumors, including prostate, ${ }^{8}$ bladder, ${ }^{31}$ gastric, ${ }^{32}$ lung, ${ }^{33}$ and breast cancer. ${ }^{34}$ EZH2 has also been implicated in cancer initiation, promotion, and progression. ${ }^{35}$ Therefore, genetic mutations may significantly influence the function of EZH2 in cancer initiation and risk. ${ }^{36}$ Cumulative studies have suggested that recurrent heterozygous point mutations affecting tyrosine 641 (Y641) in germinal center B-cell and point mutations at alanine 687 or 677 in non-Hodgkin's lymphomas can increase H3K27me3 levels, thereby repressing the expression of Polycomb targets. ${ }^{37-39}$

SNPs, as the most common genetic sequence variation, can affect the function of $E Z H 2$ and its downstream targets by altering $E Z H 2$ transcription and $\mathrm{H} 3 \mathrm{~K} 27$ trimethylation. For example, the rs 3757441 polymorphism C/C genotype is associated with strong EZH2 and H3K27me3 immunoreactivity in primary $\mathrm{CRC}$, indicating that this genotype can be a promising biomarker for EZH2-targeting agents. ${ }^{27}$ The rs887569 TT genotype is correlated with a significantly increased overall survival and a reduced risk of mortality in patients with cholangiocarcinoma. ${ }^{40}$ Zhou et $\mathrm{al}^{22}$ found that the haplotypes of EZH2 genes with minor alleles of rs12670401 and rs6464926 or major alleles of rs2072407, rs734005, and rs734004 significantly increase the risk of gastric cancer, whereas the haplotypes of EZH2 genes with major alleles of rs12670401 and rs6464926 or minor alleles of rs2072407, rs734005, and rs734004 can reduce the risk of gastric cancer. These studies have demonstrated that the SNPs of EZH2 are closely related to cancer risk and prognosis. Although studies have revealed that EZH2 polymorphisms are associated with cancer risk, results are inconsistent. Therefore, we systematically reviewed the literature through a meta-analysis of the association between $E Z H 2$ gene polymorphisms and cancer risk. To the best of our knowledge, this study is the first meta-analysis to investigate the relationship between EZH2 SNPs and cancer risk.

While searching for eligible studies, we found 11 EZH2 SNPs that were reported to be associated with cancer risk: 
rs887569, rs2302427, rs375441, rs41277434, rs6950683, rs2072407, rs734005, rs734004, rs6464926, rs12670401, and rs1880357. However, only the first 4 SNPs were examined in at least 5 individual studies. We then performed 4 genotype distributions between cases and controls. Our study included 5 articles, with a pooled total of 1,794 cases and 1,878 controls, which were relevant to the relationship between the rs887569 SNP and cancer risk. The cancer risk was significantly reduced in $\mathrm{CT} / \mathrm{TT}$ genotype relative to $\mathrm{CC}$ genotype $(\mathrm{CTTT} / \mathrm{CC}: \mathrm{OR}=0.849,95 \% \mathrm{CI}:$ [0.740 to 0.973 ], $P=0.019)$. This association was also detected in the recessive genetic model (TT/CCCT: OR $=0.793,95 \% \mathrm{CI}$ : $[0.654$ to $0.962], P=0.019)$. $Z$-scores and $P$-values were calculated to evaluate the reliability of our results, and the $P$-values of the dominant and recessive genetic models of rs887569 were 0.019 , which might strengthen our findings. We also found a significant link between rs2302427 polymorphism and cancer susceptibility in the homozygote genotype, dominant genetic, and recessive genetic models (GG/CC: $\mathrm{OR}=0.562,95 \%$ CI: [0.400 to 0.792], $P=0.001 ; \mathrm{CGGG} / \mathrm{CC}: \mathrm{OR}=0.856,95 \%$ CI: [0.748 to 0.980$], P=0.024 ; \mathrm{GG} / \mathrm{CCCG}: \mathrm{OR}=0.733$, 95\% CI: [0.571 to 0.940$], P=0.015$ ). In the subgroup analysis of ethnicity, rs2302427 CG or CG/GG genotype was significantly related to a decreased prostate cancer risk in the Caucasian population, whereas the GG genotype was closely linked to a decreased overall cancer risk in the Asian

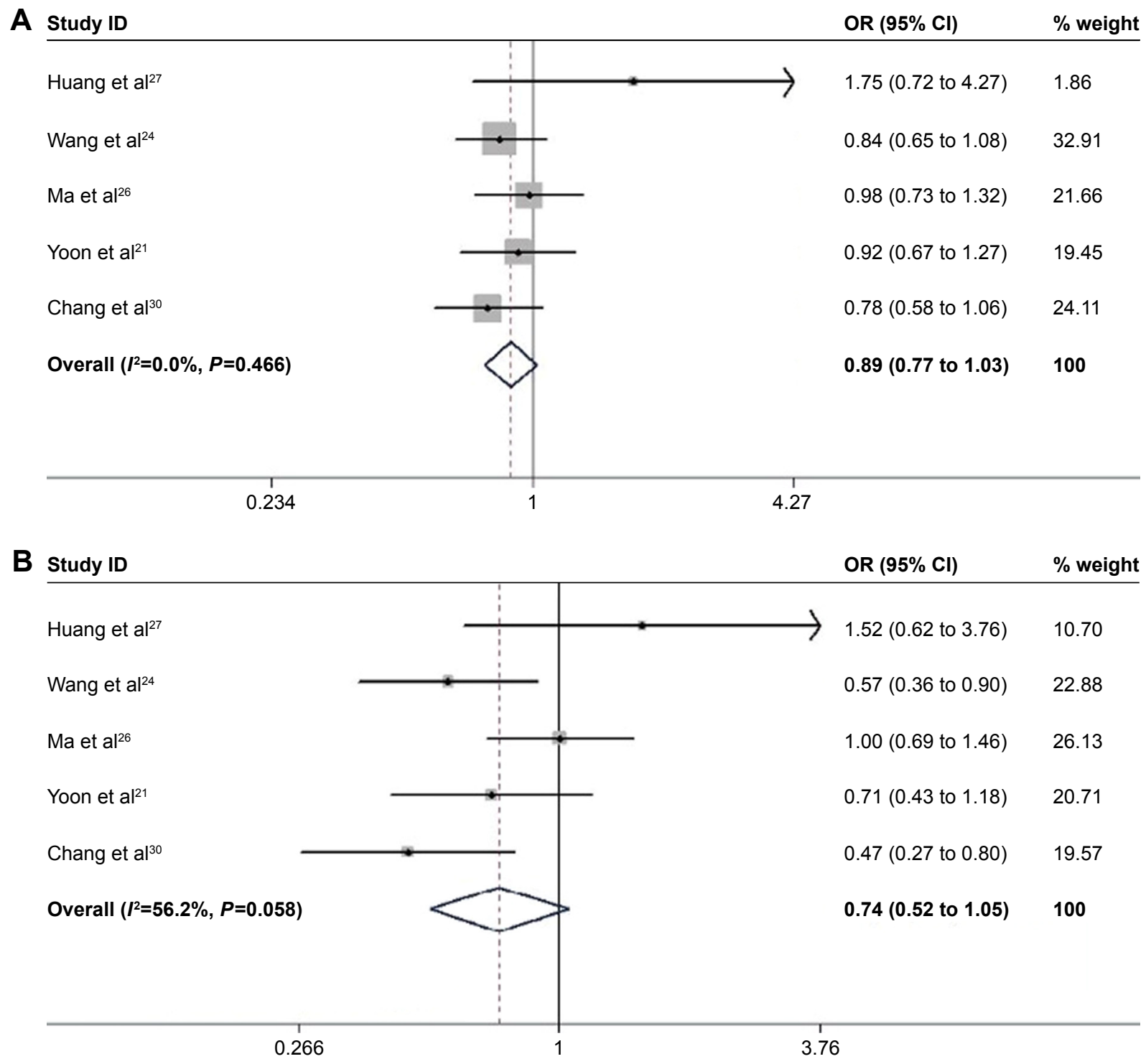

Figure 3 (Continued) 


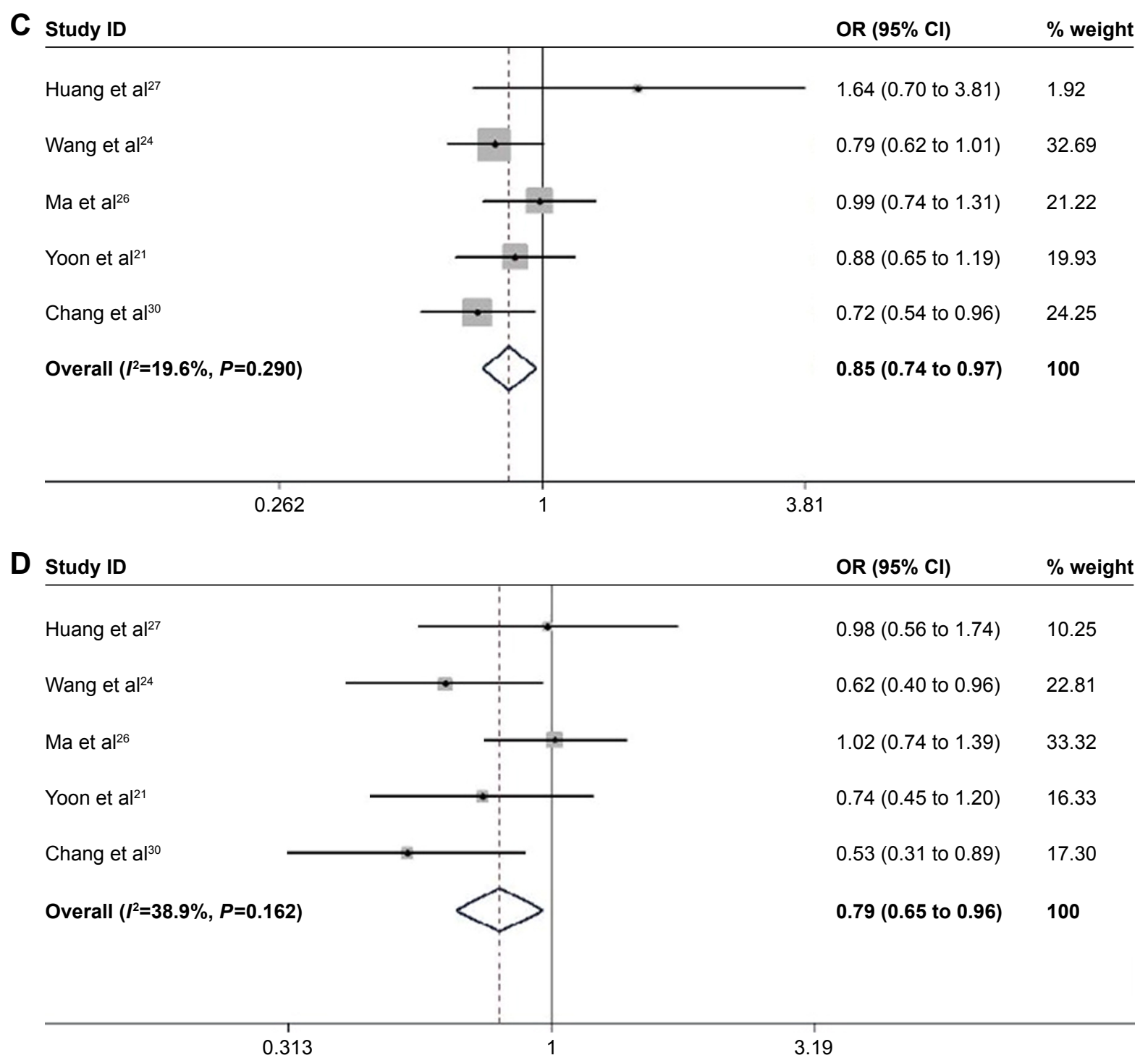

Figure 3 Forest plot for the relationship between rs887569 and cancer risk: (A) CT/CC; (B) TT/CC; (C) CTTT/CC; (D) TT/CCCT.

Note: Weights are from random effects analysis.

population. However, the reliability of our data would have improved had we enrolled more eligible studies and a larger sample size than the obtained data.

We subsequently examined the effect of EZH2 SNP rs3757441, which is a key indicator of poor prognosis in metastatic $\mathrm{CRC}$, on overall cancer risk by analyzing 9 eligible studies. ${ }^{27}$ However, in our current meta-analysis, the association between rs 3757441 and cancer risk is controversial. We also performed a stratified analysis by cancer types, but no association was observed between rs 3757441 and USC or DSC. These inconsistent results might be due to the heterogeneity of cancer type, ethnicity, and sample size, considering that rs3757441 plays a protective role in lung cancer in a Korean population ${ }^{21}$ but acts as a risk factor in CRC in a Han Chinese population. ${ }^{24}$ Furthermore, we searched for articles related to $E Z H 2$ rs 41277434 , and our results indicated that no significant association was found between rs 41277343 and overall cancer risk or DSC risk.

Sensitivity analysis revealed that the results of our study were robust. Egger's and Begg's tests indicated a publication bias in homozygote and recessive models of rs3757441 and rs41277434. Future large-scale well-designed studies should be conducted to confirm the publication bias of the genetic models of rs375441 and rs41277434.

Several limitations of our meta-analysis should be considered. First, most of the eligible studies mainly focused on East Asian populations, whereas 2 studies involved Caucasians. Studies on other ethnicities were not included in this metaanalysis. Thus, our results were incomplete. The number of eligible studies and the sample size were relatively small and 
A
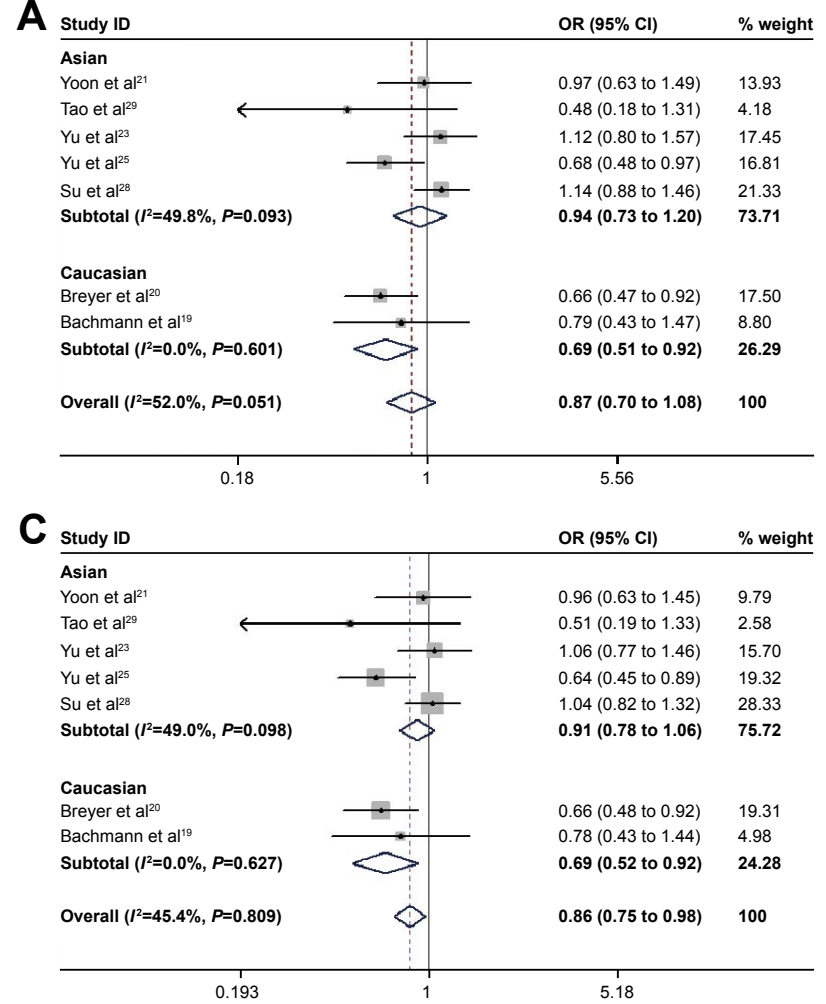

B

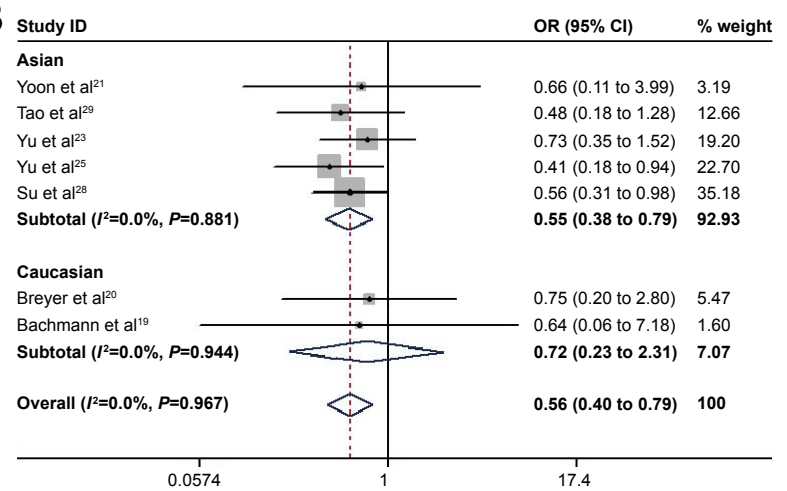

$D_{s}$

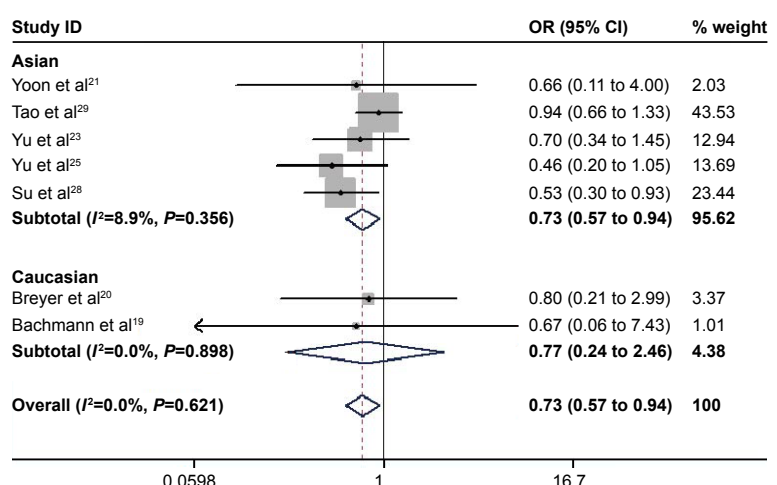

Figure 4 Forest plot for the relationship between rs2302427 and cancer risk: (A) CG/CC; (B) GG/CC; (C) CGGG/CC; (D) GG/CCCG.

Note: Weights are from random effects analysis.

might consequently cause a type II error. Second, our results were based on unadjusted estimates because of the lack of original data on age, gender, and smoking status. Potential bias caused by these factors might also persist. Third, differences among various cancers might lead to heterogeneity when all cancer types were pooled. Stratified analysis by specific cancer type was not conducted because of the insufficient number of studies on single cancer type. Finally, we only searched for publications in Chinese and English. As such, language restriction would limit our sample size.

Table 3 Publication bias in meta-analysis for each inheritance model

\begin{tabular}{|c|c|c|c|c|c|c|}
\hline \multirow[t]{2}{*}{ SNPs } & \multirow[t]{2}{*}{ Inheritance model } & \multirow[t]{2}{*}{ Studies } & \multicolumn{2}{|c|}{ Begg's test } & \multicolumn{2}{|l|}{ Egger's test } \\
\hline & & & Z-value & $P$-value & $95 \% \mathrm{Cl}$ & $P$-value \\
\hline \multirow[t]{4}{*}{ rs887569 C>T } & Heterozygote genotype: CT/CC & 5 & 0.73 & 0.462 & $(-0.54$ to 5.08$)$ & 0.082 \\
\hline & Homozygote genotype: TT/CC & 5 & 0.24 & 0.806 & $(-9.31$ to 10.11$)$ & 0.904 \\
\hline & Dominant genetic model: CTTT/CC & 5 & 0.73 & 0.462 & $(-1.75$ to 6.47$)$ & 0.165 \\
\hline & Recessive genetic model: TT/CCCT & 5 & 0.24 & 0.806 & $(-10.84$ to 5.23$)$ & 0.328 \\
\hline \multirow[t]{4}{*}{ rs2302427 C>G } & Heterozygote genotype: CG/CC & 7 & 0.60 & 0.548 & $(-5.94$ to 1.95$)$ & 0.250 \\
\hline & Homozygote genotype: GG/CC & 7 & 0.00 & 1.000 & $(-1.08$ to 1.44$)$ & 0.729 \\
\hline & Dominant genetic model: CGGG/CC & 7 & 1.20 & 0.230 & $(-5.4 \mid$ to 2.10$)$ & 0.308 \\
\hline & Recessive genetic model: GG/CCCG & 7 & 0.30 & 0.764 & $(-2.24$ to 0.91$)$ & 0.328 \\
\hline \multirow[t]{4}{*}{ rs375744I I $>C$} & Heterozygote genotype: CT/TT & 9 & 1.98 & 0.048 & $(-11.99$ to 3.87$)$ & 0.265 \\
\hline & Homozygote genotype: CC/TT & 9 & 1.77 & 0.076 & $(-13.17$ to -2.36$)$ & 0.012 \\
\hline & Dominant genetic model: CCCT/TT & 9 & 1.77 & 0.076 & $(-17.25$ to 5.26$)$ & 0.268 \\
\hline & Recessive genetic model: CC/CTTT & 9 & 1.36 & 0.175 & $(-10.34$ to -2.11$)$ & 0.009 \\
\hline \multirow[t]{4}{*}{ rs 4 I $277434 \mathrm{~A}>C$} & Heterozygote genotype: AC/AA & 7 & 0.90 & 0.368 & $(-1.66$ to 0.47$)$ & 0.212 \\
\hline & Homozygote genotype: CC/AA & 7 & 2.10 & 0.035 & $(-0.10$ to 1.17$)$ & 0.083 \\
\hline & Dominant genetic model: ACCC/AA & 7 & 1.20 & 0.230 & $(-1.56$ to 0.54$)$ & 0.263 \\
\hline & Recessive genetic model: CC/AAAC & 7 & 2.10 & 0.035 & $(-0.18$ to 1.38$)$ & 0.106 \\
\hline
\end{tabular}

Abbreviation: SNP, single nucleotide polymorphism. 


\section{Conclusion}

Despite the limitations, our meta-analysis revealed that EZH2 rs887569 and rs2302427 might be correlated with a decreased cancer risk in specific genetic models, whereas the association of EZH2 rs3757441 and rs41277434 polymorphisms with overall cancer risk was not observed. To confirm our results and provide highly reliable evidence supporting these associations, we recommend future large-scale and well-designed studies on diverse ethnic populations and cancer types.

\section{Acknowledgments}

This work was supported by grants from National Natural Science Foundation of China (NO 81672551, 81572517, 81370849, 81300472), Natural Science Foundation of Jiangsu Province (BK20161434, BL2013032, BK20150642, and BK2012336), Six Talent Peaks Project in Jiangsu Province, Jiangsu Provincial Medical Innovation Team (CXTDA2017025), Jiangsu Provincial Medical Talent (ZDRCA2016080), Jiangsu Provincial Medical Youth Talent(QNRC2016821, QRNC2016820), Graduate Research Innovation Program (KYCX17_0180).

\section{Author contributions}

ZL performed the experiments and wrote the paper. ZY performed the experiments, prepared figures, and/or tables. LH analyzed the data, prepared figures, and/or tables. LZ analyzed the data. YW reviewed drafts of the paper. MZ analyzed the data, contributed reagents/materials/analysis tools. GZ contributed reagents/materials/analysis tools and reviewed drafts of the paper. SC contributed reagents/materials/analysis tools. BX and MC conceived and designed the experiments, and reviewed drafts of the paper. All authors contributed toward data analysis, drafting and revising the paper and agree to be accountable for all aspects of the work.

\section{Disclosure}

The authors report no conflicts of interest in this work.

\section{References}

1. Siegel RL, Miller KD, Jemal A. Cancer statistics, 2017. CA Cancer J Clin. 2017;67(1):7-30.

2. Pedraza-Farina LG. Mechanisms of oncogenic cooperation in cancer initiation and metastasis. Yale J Biol Med. 2006;79(3-4):95-103.

3. Volkel P, Dupret B, Le Bourhis X, Angrand PO. Diverse involvement of EZH2 in cancer epigenetics. Am J Transl Res. 2015;7(2):175-193.

4. Di Croce L, Helin K. Transcriptional regulation by Polycomb group proteins. Nat Struct Mol Biol. 2013;20(10):1147-1155.
5. Yang Y, Zhou L, Lu L, et al. A novel miR-193a-5p-YY1-APC regulatory axis in human endometrioid endometrial adenocarcinoma. Oncogene. 2013;32(29):3432-3442.

6. Boulay G, Dubuissez M, Van Rechem C, et al. Hypermethylated in cancer 1 (HIC1) recruits polycomb repressive complex 2 (PRC2) to a subset of its target genes through interaction with human polycomb-like (hPCL) proteins. J Biol Chem. 2012;287(13):10509-10524.

7. Smits M, Nilsson J, Mir SE, et al. miR-101 is down-regulated in glioblastoma resulting in EZH2-induced proliferation, migration, and angiogenesis. Oncotarget. 2010;1(8):710-720.

8. Varambally S, Dhanasekaran SM, Zhou M, et al. The polycomb group protein $\mathrm{EZH} 2$ is involved in progression of prostate cancer. Nature. 2002;419(6907):624-629.

9. Bracken AP, Pasini D, Capra M, Prosperini E, Colli E, Helin K. EZH2 is downstream of the $\mathrm{pRB}-\mathrm{E} 2 \mathrm{~F}$ pathway, essential for proliferation and amplified in cancer. EMBO J. 2003;22(20):5323-5335.

10. Bachmann IM, Halvorsen OJ, Collett $\mathrm{K}$, et al. EZH2 expression is associated with high proliferation rate and aggressive tumor subgroups in cutaneous melanoma and cancers of the endometrium, prostate, and breast. J Clin Oncol. 2006;24(2):268-273.

11. Sauvageau M, Sauvageau G. Polycomb group proteins: multi-faceted regulators of somatic stem cells and cancer. Cell Stem Cell. 2010;7(3): 299-313.

12. Yap DB, Chu J, Berg T, et al. Somatic mutations at EZH2 Y641 act dominantly through a mechanism of selectively altered PRC2 catalytic activity, to increase H3K27 trimethylation. Blood. 2011;117(8): 2451-2459.

13. Simon C, Chagraoui J, Krosl J, et al. A key role for EZH2 and associated genes in mouse and human adult T-cell acute leukemia. Genes Dev. 2012;26(7):651-656.

14. Zhang J, Ding L, Holmfeldt L, et al. The genetic basis of early T-cell precursor acute lymphoblastic leukaemia. Nature. 2012;481(7380) $157-163$.

15. Stang A. Critical evaluation of the Newcastle-Ottawa scale for the assessment of the quality of nonrandomized studies in meta-analyses. Eur J Epidemiol. 2010;25(9):603-605.

16. Higgins JP, Thompson SG, Deeks JJ, Altman DG. Measuring inconsistency in meta-analyses. BMJ. 2003;327(7414):557-560.

17. DerSimonian R, Laird N. Meta-analysis in clinical trials. Control Clin Trials. 1986;7(3):177-188.

18. Mantel N, Haenszel W. Statistical aspects of the analysis of data from retrospective studies of disease. J Natl Cancer Inst. 1959;22(4) 719-748.

19. Bachmann N, Hoegel J, Haeusler J, et al. Mutation screen and association study of EZH2 as a susceptibility gene for aggressive prostate cancer. Prostate. 2005;65(3):252-259.

20. Breyer JP, McReynolds KM, Yaspan BL, Bradley KM, Dupont WD, Smith JR. Genetic variants and prostate cancer risk: candidate replication and exploration of viral restriction genes. Cancer Epidemiol Biomarkers Prev. 2009;18(7):2137-2144.

21. Yoon KA, Gil HJ, Han J, Park J, Lee JS. Genetic polymorphisms in the polycomb group gene EZH2 and the risk of lung cancer. $J$ Thorac Oncol. 2010;5(1):10-16.

22. Zhou Y, Du WD, Wu Q, et al. EZH2 genetic variants affect risk of gastric cancer in the Chinese Han population. Mol Carcinog. 2014; 53(8):589-597.

23. Yu YL, Su KJ, Hsieh YH, et al. Effects of EZH2 polymorphisms on susceptibility to and pathological development of hepatocellular carcinoma. PLoS One. 2013;8(9):e74870.

24. Wang J, Ma ZB, Li K, Guo GH. Association between EZH2 polymorphisms and colorectal cancer risk in Han Chinese population. Med Oncol. 2014;31(3):874.

25. Yu YL, Su KJ, Hsieh MJ, et al. Impact of EZH2 polymorphisms on urothelial cell carcinoma susceptibility and clinicopathologic features. PLoS One. 2014;9(4):e93635. 
26. Ma ZB, Guo GH, Niu Q, Shi N. Role of EZH2 polymorphisms in esophageal squamous cell carcinoma risk in Han Chinese population. Int J Mol Sci. 2014;15(7):12688-12697.

27. HuangY, WangX, ZhangL, et al. Correlations of single nucleotide polymorphisms of EZH2 gene with genetic susceptibility of colorectal cancer. Chin J Clin Lab Sci. 2015;33(4):262-265.

28. Su KJ, Lin CW, Chen MK, Yang SF, Yu YL. Effects of EZH2 promoter polymorphisms and methylation status on oral squamous cell carcinoma susceptibility and pathology. Am J Cancer Res. 2015;5(11): 3475-3484.

29. Tao R, Chen Z, Wu P, et al. The possible role of EZH2 and DNMT1 polymorphisms in sporadic triple-negative breast carcinoma in southern Chinese females. Tumour Biol. 2015;36(12):9849-9855.

30. Chang WS, Liao CH, Tsai CW, et al. Association of Enhancer of Zeste 2 (EZH2) Genotypes with Bladder Cancer Risk in Taiwan. Anticancer Res. 2016;36(9):4509-4514.

31. Arisan S, Buyuktuncer ED, Palavan-Unsal N, Caskurlu T, Cakir OO, Ergenekon E. Increased expression of EZH2, a polycomb group protein, in bladder carcinoma. Urol Int. 2005;75(3):252-257.

32. Matsukawa Y, Semba S, Kato H, Ito A, Yanagihara K, Yokozaki H. Expression of the enhancer of zeste homolog 2 is correlated with poor prognosis in human gastric cancer. Cancer Sci. 2006;97(6):484-491.

33. Watanabe H, Soejima K, Yasuda H, et al. Deregulation of histone lysine methyltransferases contributes to oncogenic transformation of human bronchoepithelial cells. Cancer Cell Int. 2008;8:15.
34. Kleer CG, Cao Q, Varambally S, et al. EZH2 is a marker of aggressive breast cancer and promotes neoplastic transformation of breast epithelial cells. Proc Natl Acad Sci U S A. 2003;100(20):11606-11611.

35. Tsang DP, Cheng AS. Epigenetic regulation of signaling pathways in cancer: role of the histone methyltransferase EZH2. J Gastroenterol Hepatol. 2011;26(1):19-27.

36. Kim KH, Roberts CW. Targeting EZH2 in cancer. Nat Med. 2016; 22(2):128-134.

37. Morin RD, Johnson NA, Severson TM, et al. Somatic mutations altering EZH2 (Tyr641) in follicular and diffuse large B-cell lymphomas of germinal-center origin. Nat Genet. 2010;42(2):181-185.

38. Majer CR, Jin L, Scott MP, et al. A687V EZH2 is a gain-of-function mutation found in lymphoma patients. FEBS Lett. 2012;586(19): 3448-3451.

39. McCabe MT, Graves AP, Ganji G, et al. Mutation of A677 in histone methyltransferase EZH2 in human B-cell lymphoma promotes hypertrimethylation of histone $\mathrm{H} 3$ on lysine 27 (H3K27). Proc Natl Acad Sci US A. 2012;109(8):2989-2994.

40. Paolicchi E, Pacetti P, Giovannetti E, et al. A single nucleotide polymorphism in $\mathrm{EZH} 2$ predicts overall survival rate in patients with cholangiocarcinoma. Oncol Lett. 2013;6(5):1487-1491. 


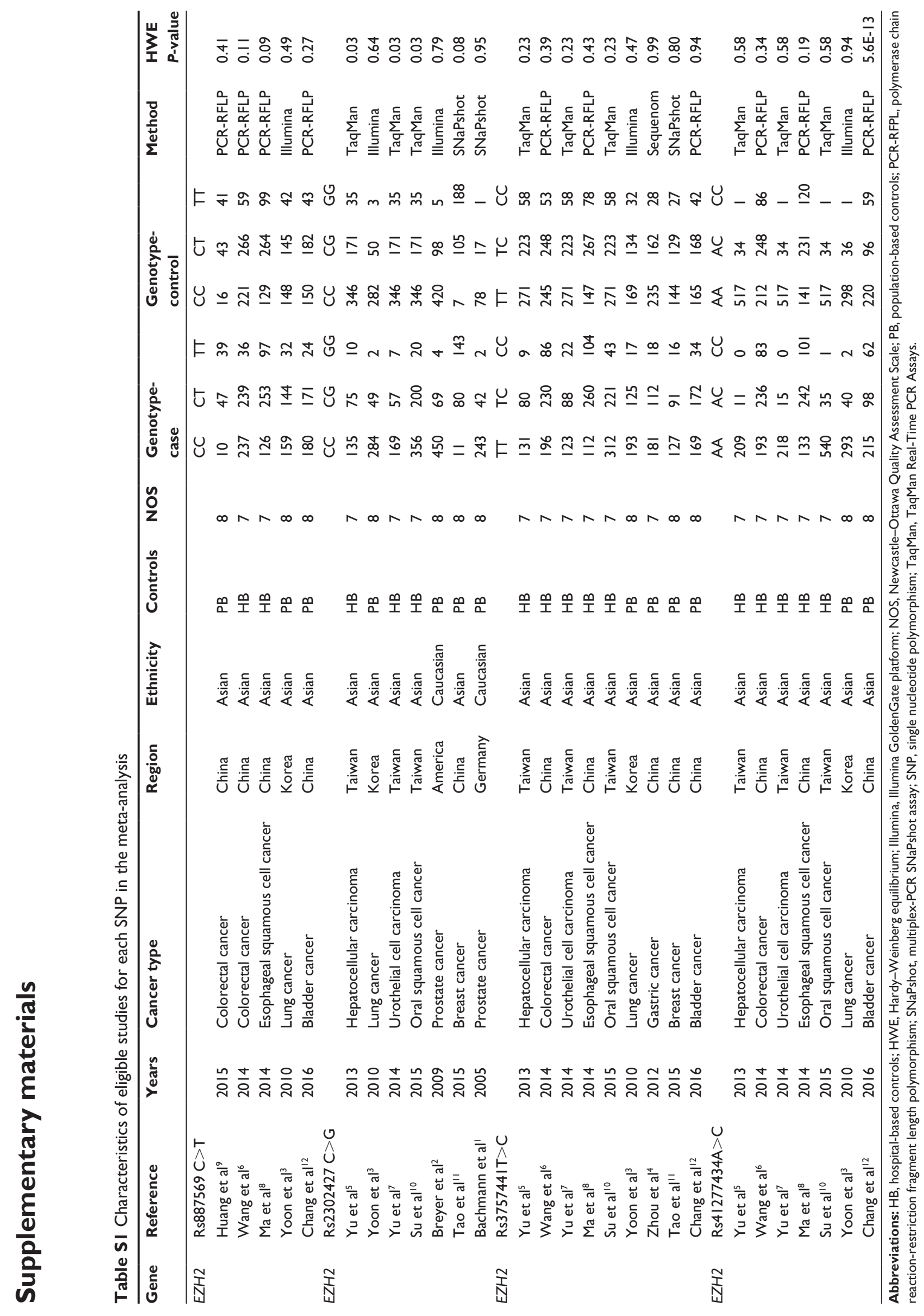


A

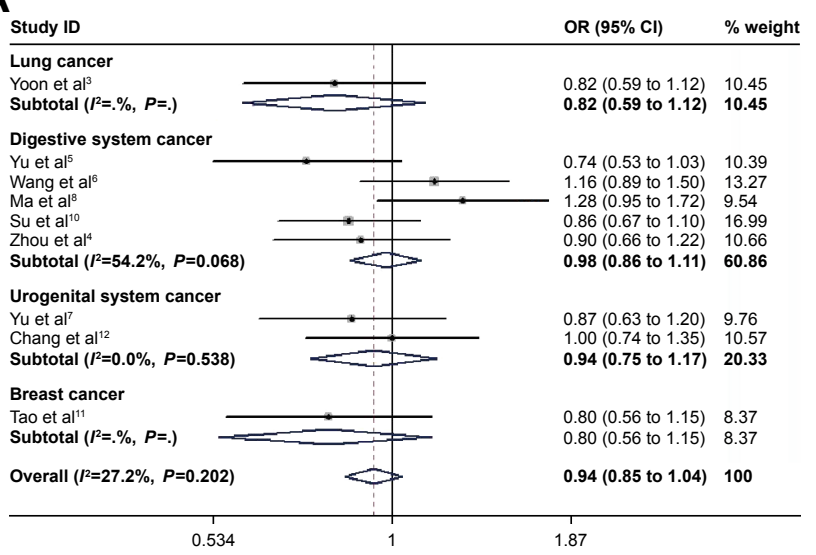

C

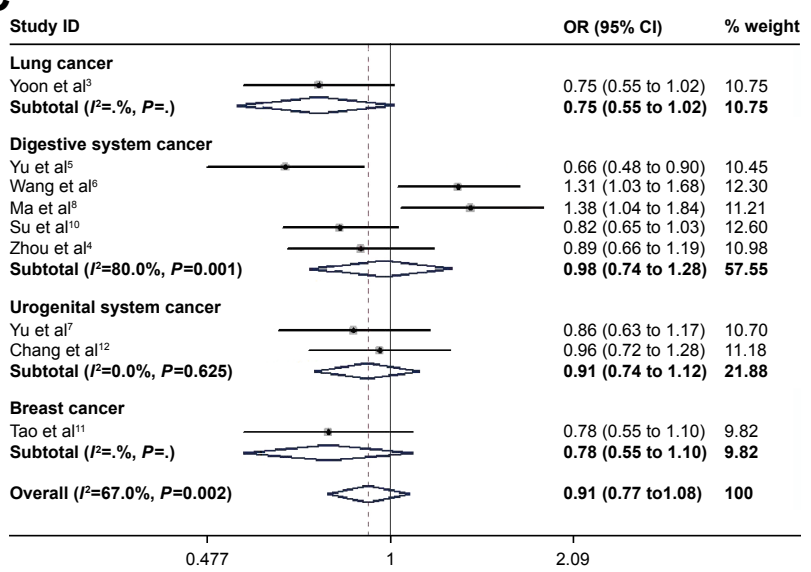

B

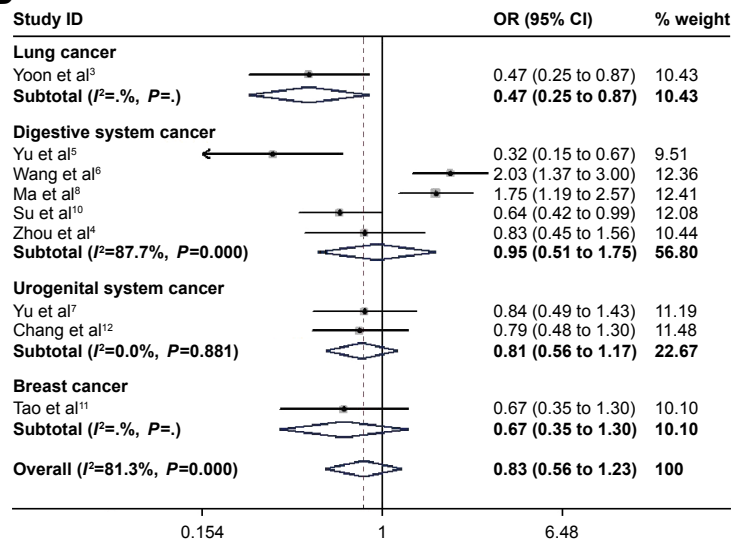

D

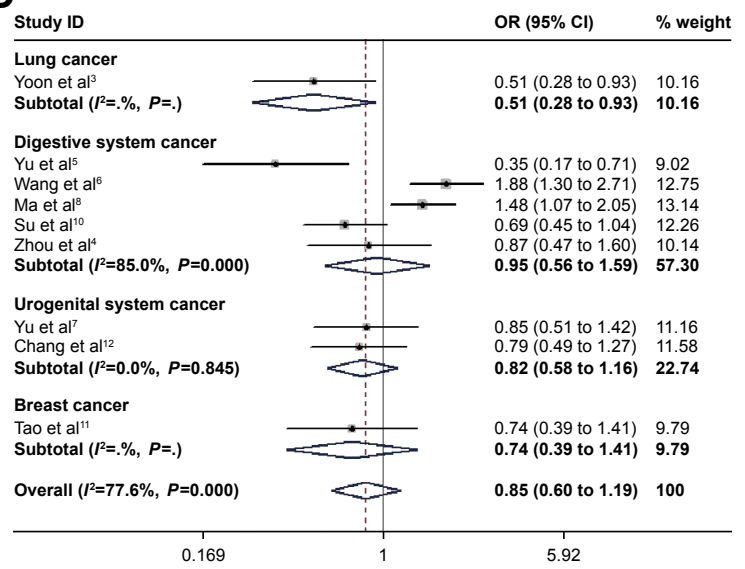

Figure SI Forest plot for the relationship between rs375744I and cancer risk: (A) CT/TT; (B) CC/TT; (C) CCCT/TT; (D) CC/CTTT. Note: Weights are from random effects analysis. 
A

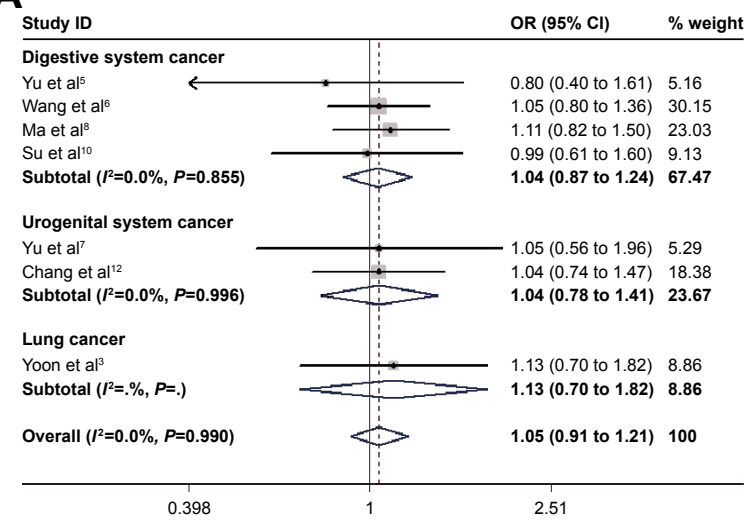

C

$$
\text { Study ID }
$$

Digestive system cancer

Yu et al ${ }^{5}$

Wang et al ${ }^{6}$

Ma et $a^{9}$

Su et al ${ }^{10}$

Subtotal $\left(I^{2}=0.0 \%, P=0.881\right)$

Urogenital system cancer

Yu et al ${ }^{7}$

Chang et al ${ }^{12}$

Subtotal $\left(I^{2}=0.0 \%, P=0.913\right)$

Lung cancer

Yoon et al ${ }^{3}$

Subtotal $\left(I^{2}=. \%, P=\right.$.)

Overall $\left(I^{2}=0.0 \%, P=0.988\right)$

0.388

OR $(95 \% \mathrm{Cl}) \quad \%$ weight

B

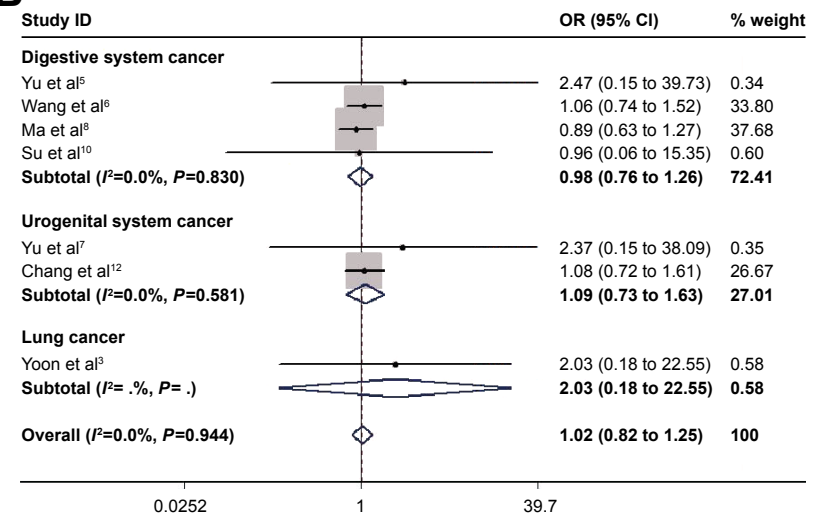

D

\begin{tabular}{|c|c|c|c|}
\hline Study ID & & OR $(95 \% \mathrm{Cl})$ & $\%$ weight \\
\hline \multicolumn{4}{|l|}{ Digestive system cancer } \\
\hline Yu et al ${ }^{5}$ & & $2.50(0.16$ to 40.22$)$ & 0.26 \\
\hline Wang et $\left.a\right|^{6}$ & & $1.03(0.74$ to 1.44$)$ & 32.42 \\
\hline Ma et $\mathrm{al}^{8}$ & $\rightarrow$ & $0.83(0.62$ to 1.13$)$ & 43.22 \\
\hline Su et $a^{10}$ & & 0.96 (0.06 to 15.36$)$ & 0.47 \\
\hline Subtotal $\left(I^{2}=0.0 \%, P=0.709\right)$ & $\phi$ & $0.93(0.74$ to 1.15$)$ & 76.37 \\
\hline \multicolumn{4}{|l|}{ Urogenital system cancer } \\
\hline Yu et $\mathrm{al}^{7}$ & & $2.36(0.15$ to 37.97$)$ & 0.28 \\
\hline Chang et al ${ }^{12}$ & - & $1.06(0.72$ to 1.57$)$ & 22.89 \\
\hline Subtotal $\left(I^{2}=0.0 \%, P=0.575\right)$ & $\infty$ & $1.08(0.73$ to 1.58$)$ & 23.17 \\
\hline \multicolumn{4}{|l|}{ Lung cancer } \\
\hline Yoon et $a^{3}$ & & 2.01 (0.18 to 22.23$)$ & 0.46 \\
\hline Subtotal $\left(I^{2}=. \%, P=.\right)$ & 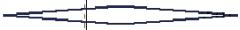 & $2.01(0.18$ to 22.23$)$ & 0.46 \\
\hline Overall $\left(I^{2}=0.0 \%, P=0.869\right)$ & $\phi$ & $0.97(0.80$ to 1.17$)$ & 100 \\
\hline 0.0249 & 1 & & \\
\hline
\end{tabular}

Figure S2 Forest plot for the relationship between rs4I277434 and cancer risk: (A) AC/AA; (B) CC/AA; (C) ACCC/AA; (D) CC/AAAC. 

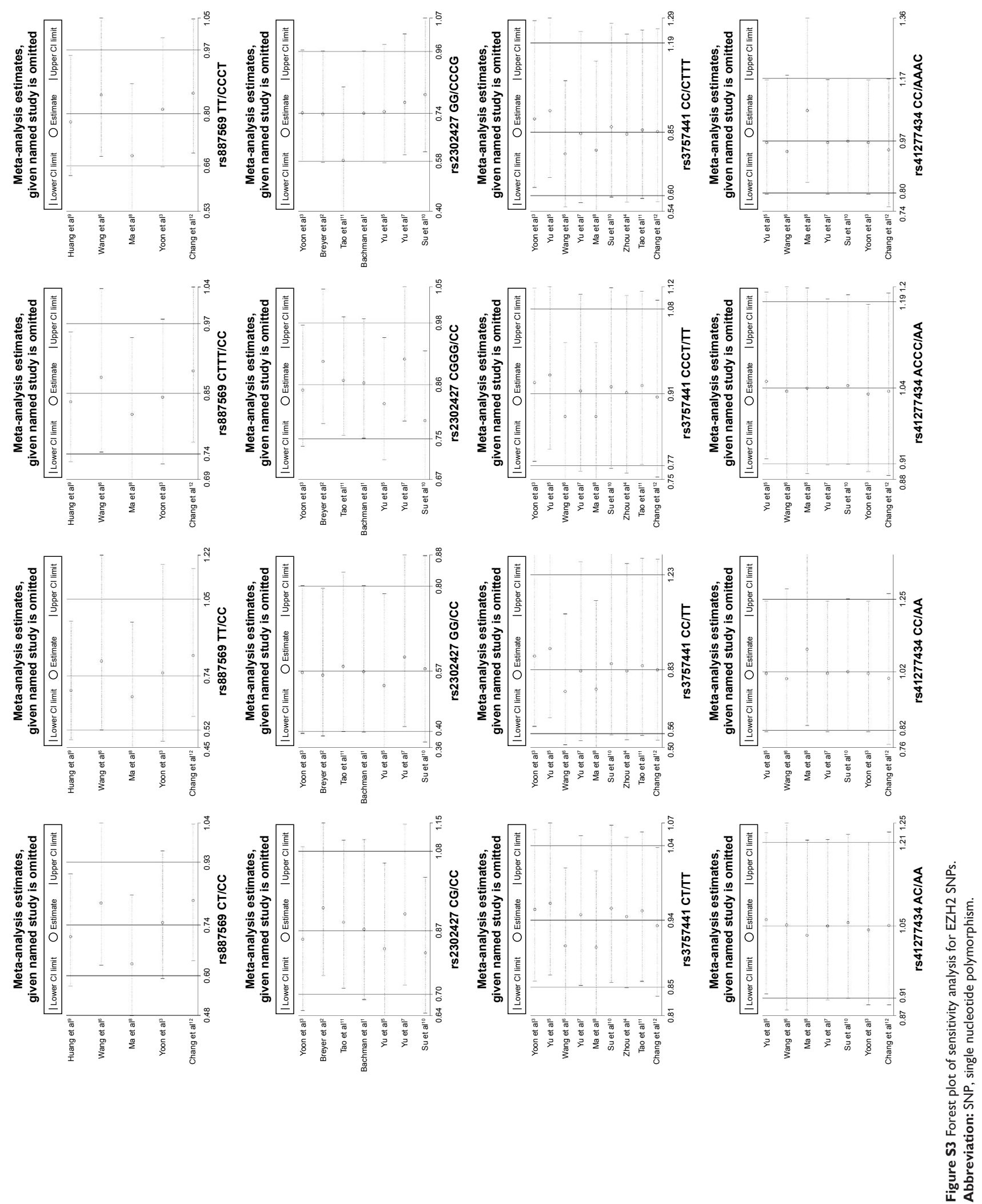


\section{References}

1. Bachmann N, Hoegel J, Haeusler J, et al. Mutation screen and association study of EZH2 as a susceptibility gene for aggressive prostate cancer. Prostate. 2005;65(3):252-259.

2. Breyer JP, McReynolds KM, Yaspan BL, Bradley KM, Dupont WD, Smith JR. Genetic variants and prostate cancer risk: candidate replication and exploration of viral restriction genes. Cancer Epidemiol Biomarkers Prev. 2009;18(7):2137-2144.

3. Yoon KA, Gil HJ, Han J, Park J, Lee JS. Genetic polymorphisms in the polycomb group gene EZH2 and the risk of lung cancer. J Thorac Oncol. 2010;5(1):10-16.

4. Zhou Y, Du WD, Wu Q, et al. EZH2 genetic variants affect risk of gastric cancer in the Chinese Han population. Mol Carcinog. 2014;53(8):589-597.

5. Yu YL, Su KJ, Hsieh YH, et al. Effects of EZH2 polymorphisms on susceptibility to and pathological development of hepatocellular carcinoma. PLoS One. 2013;8(9):e74870.

6. Wang J, Ma ZB, Li K, Guo GH. Association between EZH2 polymorphisms and colorectal cancer risk in Han Chinese population. Med Oncol. 2014;31(3):874.
7. Yu YL, Su KJ, Hsieh MJ, et al. Impact of EZH2 polymorphisms on urothelial cell carcinoma susceptibility and clinicopathologic features. PLoS One. 2014;9(4):e93635.

8. Ma ZB, Guo GH, Niu Q, Shi N. Role of EZH2 polymorphisms in esophageal squamous cell carcinoma risk in Han Chinese population. Int J Mol Sci. 2014;15(7):12688-12697.

9. Huang Y, Wang X, Zhang L, et al. Correlations of single nucleotide polymorphisms of EZH2 gene with genetic susceptibility of colorectal cancer. Chin J Clin Lab Sci. 2015;33(4):262-265.

10. Su KJ, Lin CW, Chen MK, Yang SF, Yu YL. Effects of EZH2 promoter polymorphisms and methylation status on oral squamous cell carcinoma susceptibility and pathology. Am J Cancer Res. 2015;5(11): 3475-3484.

11. Tao R, Chen Z, Wu P, et al. The possible role of EZH2 and DNMT1 polymorphisms in sporadic triple-negative breast carcinoma in southern Chinese females. Tumour Biol. 2015;36(12):9849-9855.

12. Chang WS, Liao CH, Tsai CW, et al. Association of Enhancer of Zeste 2 (EZH2) Genotypes with Bladder Cancer Risk in Taiwan. Anticancer Res. 2016;36(9):4509-4514.
OncoTargets and Therapy

\section{Publish your work in this journal}

OncoTargets and Therapy is an international, peer-reviewed, open access journal focusing on the pathological basis of all cancers, potential targets for therapy and treatment protocols employed to improve the management of cancer patients. The journal also focuses on the impact of management programs and new therapeutic agents and protocols on

\section{Dovepress}

patient perspectives such as quality of life, adherence and satisfaction. The manuscript management system is completely online and includes a very quick and fair peer-review system, which is all easy to use. Visit http://www.dovepress.com/testimonials.php to read real quotes from published authors. 